\title{
Social trends in singleton births and birth weight in Wirral residents, 1990-2001
}

\author{
P Bundred, D Manning, B Brewster, I Buchan
}

Arch Dis Child Fetal Neonatal Ed 2003;88:F421-F425

See end of article for authors' affiliations ....................

Correspondence to: Dr Bundred, Department of Primary Care, Whelan Building, University of Liverpool, Liverpool L69 3GB, UK; peterb@liv.ac.uk

Accepted

28 October 2002

\begin{abstract}
Objective: To examine social trends in the number of singleton births and birth weight in an English health district between 1990 and 2001, using an area based deprivation index.

Design: Analysis of routinely collected hospital data.

Setting: Wirral Health District in north west England.

Participants: All 48452 live births to Wirral residents from 1990 to 2001.

Main outcome measures: Birth numbers, birth weight, and standard deviation score for birth weights for singleton births. Townsend material deprivation scores derived from postcodes.

Results: The number of singleton births fell by $28 \%$ over the 12 years. The fall in the least deprived Townsend quartile $(45 \%)$ was more than triple that in the most deprived quartile $(\gamma=0.045 ; 95 \%$ confidence interval $(\mathrm{Cl})=0.036$ to $0.054 ; \mathrm{p}<0.001)$. Over the study period, the mean birth weight in the least deprived Townsend quartile was $141 \mathrm{~g}$ higher than in the most deprived quartile. There was a highly significant association between the standard deviation score for birth weight and Townsend quartile $(\tau-b=-0.062 ; 95 \% \mathrm{Cl}=-0.068$ to $-0.055 ; p<0.001)$. Numbers of low birth weight babies in the least deprived quartile fell disproportionately compared with those from the most deprived quartile $(\gamma=0.17 ; 95 \% \mathrm{Cl}=0.09$ to $0.25 ; \mathrm{p}<0.001)$.

Conclusion: The reduction in birth rate in the Wirral was significantly less in the most deprived districts. This was accompanied by related differences in mean birth weight and the number of low birth weight babies, indicating increasing social inequality in birth trends. Previously described social ineqvity in birth weight and the number of low birth weight babies continues in the north west of England.
\end{abstract}

$\mathrm{D}$ uring the last decade the number of live births in England and Wales fell steadily, from 706140 in 1990 to 604441 in $2000 .{ }^{1}$ Little is known about the social class distribution of this trend. The Office for National Statistics (ONS), using the Registrar General's social classification, reported that the reduction in live births was greater among more deprived than among less deprived families. ${ }^{2}$ This classification has limitations because it depends on the father's occupation for jointly registered births. It therefore excludes one of the most vulnerable social groups, babies born to single mothers. An area based deprivation score has been argued to be a better discriminator of pregnancy outcome than occupational classification. ${ }^{3}$

As birth weight is strongly influenced by social class, ${ }^{2}$ socioeconomic differences in birth trends could influence the incidence of low birth weight. Using a 10\% sample of live births, the ONS shows a progressive increase in live births weighing less than $2500 \mathrm{~g}$ between 1994 and 2000. This increase occurred in all social classes but was greater in manual than non-manual groups. ${ }^{2}$

The objective of this study was to examine social trends in numbers of singleton births and in birth weight in an English health district between 1990 and 2001, using an area based deprivation index, the Townsend material deprivation score. ${ }^{4}$

From a public health perspective a smaller reduction in live births among more deprived families, or a relative increase in low birth weight in this group, would be important, because area based deprivation and low birth weight are significantly associated with adverse outcomes in the perinatal period and later infancy. ${ }^{56}$

\section{METHODS}

Wirral, the area studied, has a stable population of about 340000 with fewer than $1 \%$ from ethnic minorities. Socioeconomically the population structure is comparable to all
England. Over the 12 years of the study there were no changes in the boundaries of the district.

Data on live births to Wirral residents between 1 January 1990 and 31 December 2001 were obtained from the Wirral Hospital database. This database includes births outside the district to Wirral residents. Data collected included the home postcode of the mother at the time of birth, birth weight, gestational age, sex, and whether the pregnancy was single or multiple.

Birth weight was measured electronically with the baby naked. For birth weight measurements, only singleton births were analysed. Ideally gestational age is measured using an ultrasound scan. Early in the study, scans were not routinely carried out on mothers, and the gestational age was calculated from the date of the last menstrual period. Routine scanning at 12 weeks gestation was introduced in the later years of the study and was carried out in all pregnancies from 1999 onwards. The birth weights and gestational age were converted into standard deviation scores (SDS) using software obtained from the Child Growth Foundation.'

The mothers' postcodes were converted into Townsend material deprivation scores, ${ }^{4}$ using the Postcode to Enumerated District data set obtained from Manchester Information and Associated Services. ${ }^{8}$ These scores were then ranked in quartiles, the upper quartile indicating the most deprived quartile.

Relations between ordered birth counts (by Townsend quartile and year) were examined using the GoodmanKruskal $\gamma$ statistic as a measure of ordinal association with a 95\% confidence interval. ${ }^{9}$ Relations between continuous data

Abbreviations: ONS, Office for National Statistics; SDS, standard deviation scores; $\mathrm{Cl}$, confidence interval 


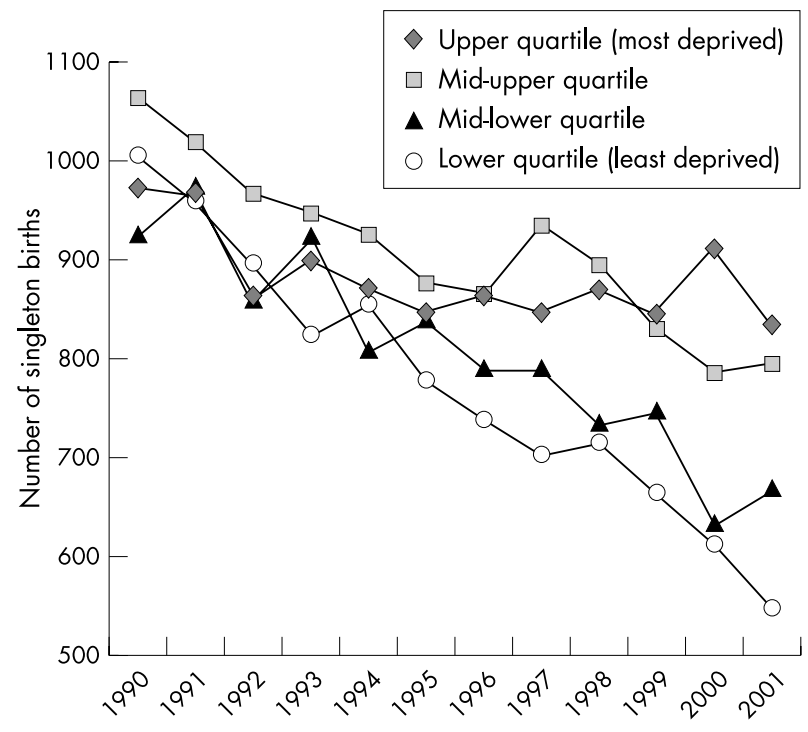

Figure 1 Change in the number of singleton births in each Townsend quartile between 1990 and 2001.

Table 1 Sex distribution of singleton births

\begin{tabular}{llllll}
\hline Year & Males & $\begin{array}{l}\text { Percentage } \\
\text { male }\end{array}$ & Females & $\begin{array}{l}\text { Percentage } \\
\text { female }\end{array}$ & $\begin{array}{l}\text { Sex ratio } \\
\text { (M:F) }\end{array}$ \\
\hline 1990 & 2083 & 52.5 & 1886 & 47.5 & 1.11 \\
1991 & 2014 & 51.4 & 1902 & 48.6 & 1.06 \\
1992 & 1923 & 53.6 & 1665 & 46.4 & 1.16 \\
1993 & 1825 & 50.8 & 1771 & 49.2 & 1.03 \\
1994 & 1799 & 52.0 & 1661 & 48.0 & 1.08 \\
1995 & 1724 & 51.6 & 1619 & 48.4 & 1.07 \\
1996 & 1699 & 52.2 & 1555 & 47.8 & 1.09 \\
1997 & 1618 & 49.5 & 1651 & 50.5 & 0.98 \\
1998 & 1647 & 51.1 & 1574 & 48.9 & 1.04 \\
1999 & 1532 & 49.6 & 1556 & 50.4 & 0.98 \\
2000 & 1481 & 50.4 & 1459 & 49.6 & 1.02 \\
2001 & 1450 & 50.9 & 1399 & 49.1 & 1.04 \\
& & & & & \\
Overall & 20795 & 51.4 & 19698 & 48.6 & 1.06 \\
\hline
\end{tabular}

(weights and SDS) and ordered categorical data (Townsend quartile) were examined using Kendall's $\tau$-b measure of rank interdependence. ${ }^{10}$ The $\gamma$ and $\tau$-b statistics measure the strength of association between two variables without assum- ing any particular distributions of the data. Time trends in weights and SDS by deprivation group were examined using analysis of covariance. ${ }^{11}$ Calculations were performed using StatsDirect software. ${ }^{12}$ Calculated probabilities are quoted to a minimum of 0.001 , values below which we refer to as highly significant.

Ethical approval to carry out this research was obtained from the Wirral ethics committee.

\section{RESULTS}

There were 48452 live births to Wirral residents from 1990 to 2001. The annual number of live births fell from 5013 in 1990 to 3137 in 2001 (37\%). Over the study period there was a $6 \%$ fall in the population of female residents aged 15-45. The 1193 multiple births during the study period were excluded from the main analysis. A further 3044 births had no birth weight recorded in the database, and 3245 records did not have a valid postcode. The overall number of exclusions was 7959, representing $16.4 \%$ of all births during the study period. Quality of data coding and processing improved progressively, with $21 \%$ of data excluded in 1990 falling to $9 \%$ in 2001 .

The number of singleton live births fell consistently during the study period (fig 1). The overall percentage fall was $28 \%$. The change in the lower Townsend (least deprived) quartile $(45 \%)$ was more than triple that in the upper (most deprived) quartile $(14 \%)$. There was a highly significant association between Townsend quartile and the reduction in birth numbers over time $(\gamma=0.045 ; 95 \%$ confidence interval $(\mathrm{CI})=0.036$ to $0.054 ; \mathrm{p}<0.001)$. There was a significant fall in the proportion of male births, from $52.5 \%$ in 1990 to $50.9 \%$ in 2001 (table 1) $(\gamma=0.018 ; 95 \% \mathrm{CI}=0.006$ to 0.030 ; $\mathrm{p}=0.04)$

There was a small and non-significant increase in the annual mean birth weight (table 2). Throughout the study period, mean birth weight was $141 \mathrm{~g}$ higher in the lower than the upper Townsend quartile (table 2 ). There was a highly significant association between birth weight and Townsend quartile $(\tau-\mathrm{b}=-0.66 ; 95 \% \mathrm{CI}=-0.72$ to $-0.60 ; \mathrm{p}<0.001)$.

Table 3 shows the mean SDS for birth weights in the four Townsend quartiles. The SDS corrects for the gestational age of the infant. A SDS of 0 represents the 50th centile, and negative scores indicate that the infant was below the national mean birth weight for gestational age. The only negative scores were seen in the upper quartile. There was a small, non-significant increase in the mean SDS for all babies born during the study period. There was a highly significant association between SDS for birth weight and Townsend quartile $(\tau-\mathrm{b}=-0.062 ; 95 \% \mathrm{CI}=-0.068$ to $-0.055 ; \mathrm{p}<0.001)$.

\begin{tabular}{|c|c|c|c|c|c|c|}
\hline \multirow[b]{2}{*}{ Year } & \multirow[b]{2}{*}{$\begin{array}{l}\text { Mean weight } \\
\text { all births }\end{array}$} & \multicolumn{4}{|c|}{ Townsend material deprivation score } & \multirow[b]{2}{*}{$\begin{array}{l}\text { Difference in } \\
\mathrm{g}(\mathrm{LQ}-\cup Q)\end{array}$} \\
\hline & & $\begin{array}{l}\text { Lower } \\
\text { quartile (LQ) }\end{array}$ & $\begin{array}{l}\text { Mid-lower } \\
\text { quartile }\end{array}$ & $\begin{array}{l}\text { Mid-upper } \\
\text { quartile }\end{array}$ & $\begin{array}{l}\text { Upper } \\
\text { quartile (UQ) }\end{array}$ & \\
\hline 1990 & 3391 & 3457 & 3435 & 3359 & 3316 & 141 \\
\hline 1991 & 3408 & 3436 & 3449 & 3407 & 3342 & 94 \\
\hline 1992 & 3422 & 3456 & 3427 & 3446 & 3356 & 100 \\
\hline 1993 & 3394 & 3447 & 3413 & 3421 & 3298 & 149 \\
\hline 1994 & 3417 & 3484 & 3434 & 3425 & 3329 & 155 \\
\hline 1995 & 3409 & 3480 & 3455 & 3396 & 3313 & 167 \\
\hline 1996 & 3406 & 3483 & 3418 & 3403 & 3332 & 151 \\
\hline 1997 & 3399 & 3473 & 3436 & 3396 & 3305 & 168 \\
\hline 1998 & 3413 & 3497 & 3426 & 3416 & 3330 & 167 \\
\hline 1999 & 3416 & 3497 & 3450 & 3398 & 3339 & 158 \\
\hline 2000 & 3434 & 3494 & 3424 & 3463 & 3375 & 119 \\
\hline 2001 & 3407 & 3463 & 3425 & 3425 & 3337 & 126 \\
\hline
\end{tabular}


Table 3 Mean standard deviation scores for singleton births in the Townsend quartiles

\begin{tabular}{llllll}
\hline Year & $\begin{array}{l}\text { Lower } \\
\text { quartile }\end{array}$ & $\begin{array}{l}\text { Mid-lower } \\
\text { quartile }\end{array}$ & $\begin{array}{l}\text { Mid-upper } \\
\text { quartile }\end{array}$ & $\begin{array}{l}\text { Upper } \\
\text { quartile }\end{array}$ & All \\
\hline 1990 & 0.18 & 0.16 & 0.02 & -0.03 & 0.08 \\
1991 & 0.18 & 0.17 & 0.09 & -0.02 & 0.11 \\
1992 & 0.18 & 0.13 & 0.17 & 0.07 & 0.14 \\
1993 & 0.22 & 0.12 & 0.08 & -0.09 & 0.08 \\
1994 & 0.25 & 0.19 & 0.11 & 0.00 & 0.13 \\
1995 & 0.23 & 0.16 & 0.11 & -0.04 & 0.11 \\
1996 & 0.23 & 0.12 & 0.04 & -0.02 & 0.09 \\
1997 & 0.12 & 0.13 & 0.06 & -0.12 & 0.04 \\
1998 & 0.19 & 0.10 & 0.08 & -0.09 & 0.06 \\
1999 & 0.24 & 0.15 & 0.13 & -0.01 & 0.12 \\
2000 & 0.29 & 0.20 & 0.24 & 0.07 & 0.19 \\
2001 & 0.26 & 0.18 & 0.21 & 0.07 & 0.17 \\
\hline
\end{tabular}

Table 4 shows the numbers and percentage of singleton low $(<2500 \mathrm{~g})$ and very low $(<1500 \mathrm{~g})$ birth weights. The absolute number of low birth weight babies fell significantly $(\tau-b=-0.56 ; 95 \% C I=-0.99$ to $-0.14 ; p=0.009)$, although as a percentage of singleton live births there has been no significant change. No significant time trends were seen for very low birthweight babies.

There was a highly significant association between Townsend quartile and annual trend in numbers of low birth weight $(\gamma=0.08 ; 95 \% \mathrm{CI}=0.04$ to $0.12 ; \mathrm{p}<0.001)$ but not of very low birth weight $(\gamma=0.07 ; 95 \% \mathrm{CI}=-0.06$ to 0.20 ; $\mathrm{p}<0.3$ ) babies. Numbers of low birth weight babies in the least deprived quartile fell disproportionately compared with those from the most deprived quartile $(\gamma=0.17 ; 95 \%$ $\mathrm{CI}=0.09$ to $0.25 ; \mathrm{p}<0.001)$. The proportion of low birth weight babies in the least deprived quartile fell significantly $(\gamma=0.08 ; 95 \% \mathrm{CI}=0.01$ to $0.15 ; \mathrm{p}=0.03)$, whereas the same proportion from the most deprived quartile did not $(\gamma=-0.01 ; 95 \% \mathrm{CI}=-0.06$ to $0.04 ; \mathrm{p}=0.66)$. There was no significant difference between these quartiles for changes over time in the numbers of very low birth weight babies. The results for the very low birth weight data, considering the small numbers involved, did not change by using exact (permutational) methods of analysis.

\section{DISCUSSION}

Studying trends in births between 1990 and 2001, we have shown that the fall in crude birth rate for singleton births on the Wirral (28\%) was greater than that for England and Wales
$(12 \%)$. The significant change in the male to female ratio follows a pattern seen throughout Europe for which there is no apparent explanation. ${ }^{13}$ There was a considerable socioeconomic difference in that the crude birth rate in the least deprived areas fell by three times $(45 \%)$ the rate in the most deprived areas (14\%).

We have also shown a socioeconomic difference in birth weight trends. When these were corrected for gestational age using SDS, the significant upward trend in mean SDS for birth weight in the least deprived quartile was matched with virtually no change in the most deprived quartile. Elmén et $^{1 l^{14}}$ have suggested that birth weight standardised for gestational age is an important health indicator, as it correlates closely with socioeconomic area indicators and mortality. There was also a significant reduction in the percentage of babies in the least deprived quartile weighing less than $2500 \mathrm{~g}$, whereas the percentage in the most deprived quartile did not change significantly. No significant time trends were seen for babies weighing less than $1500 \mathrm{~g}$, but the numbers involved were not large enough to give strong conclusions.

Spencer et al, ${ }^{15}$ using the Townsend material deprivation score, found no social trends in numbers of live births in Sheffield between 1985 and 1994. The difference from our results may reflect an interdistrict difference or we may have identified a more recent trend. This could be addressed by monitoring national trends in birth numbers by postcode and area deprivation measurement.

Our findings, which showed a smaller reduction in the number of low birth weight babies in the most deprived quartile, are consistent with the ONS report. ${ }^{2}$ Earlier research had suggested a national increase in mean birth weight in the preceding 30 years, particularly among the most disadvantaged. ${ }^{16}$

The smaller reduction in births in the most deprived quartile has great public health significance. Bambang et $a l^{5}$ reported a significant association between area based deprivation and perinatal deaths in the West Midlands. Guildea et al ${ }^{6}$ reported similar findings in Wales and also showed that deprivation was a significant risk factor for post-neonatal infant mortality. Also, Dowding and Barry ${ }^{17}$ have shown a clear social gradient in the overall prevalence of cerebral palsy in the Eastern Health Board in Ireland.

Low birth weight is associated with other adversity. Richards et al, ${ }^{18}$ in a longitudinal study of the 1946 British birth cohort, showed that birth weight was significantly positively correlated with cognitive function and educational attainment at age 8 years. Matte $e t$ a $l^{19}$ have recently shown that even in the normal ranges of birth weight there is a proportional increase in intelligence quotient (IQ) with increasing weight.

Table 4 Number and percentage of low birth weight $(<2500 \mathrm{~g})$ and very low birth weight $(<1500 \mathrm{~g}$ ) singleton babies in the lower and upper Townsend quartiles (as a percentage of singleton births in those quartiles)

\begin{tabular}{|c|c|c|c|c|c|c|}
\hline \multirow[b]{2}{*}{ Year } & \multicolumn{3}{|c|}{ Low birth weight } & \multicolumn{3}{|c|}{ Very low birth weight } \\
\hline & $\begin{array}{l}\text { All } \\
\text { singletons }\end{array}$ & $\begin{array}{l}\text { Lower } \\
\text { quartile }\end{array}$ & $\begin{array}{l}\text { Upper } \\
\text { quartile }\end{array}$ & $\begin{array}{l}\text { All } \\
\text { singletons }\end{array}$ & $\begin{array}{l}\text { Lower } \\
\text { quartile }\end{array}$ & $\begin{array}{l}\text { Upper } \\
\text { quartile }\end{array}$ \\
\hline 1990 & $216(5.44)$ & $46(4.57)$ & 64 (6.57) & $21(0.53)$ & $6(0.60)$ & $6(0.62)$ \\
\hline 1991 & 196 (5.01) & $50(5.22)$ & $58(6.01)$ & $18(0.46)$ & $4(0.42)$ & $4(0.41)$ \\
\hline 1992 & 155 (4.32) & $33(3.68)$ & $38(4.40)$ & $15(0.42)$ & $2(0.22)$ & $4(0.46)$ \\
\hline 1993 & $192(5.34)$ & 32 (3.88) & $68(7.56)$ & $18(0.50)$ & $2(0.24)$ & $11(1.22)$ \\
\hline 1994 & 138 (3.99) & $24(2.80)$ & $56(6.43)$ & $19(0.55)$ & $1(0.12)$ & $8(0.92)$ \\
\hline 1995 & 177 (5.29) & $29(3.72)$ & $61(7.20)$ & $20(0.60)$ & $0(0.00)$ & $7(0.83)$ \\
\hline 1996 & $171(5.26)$ & $28(3.79)$ & $71(8.22)$ & $14(0.43)$ & $3(0.41)$ & $3(0.35)$ \\
\hline 1997 & 165 (5.05) & $26(3.70)$ & $50(5.90)$ & $19(0.58)$ & $1(0.14)$ & $8(0.94)$ \\
\hline 1998 & $171(5.31)$ & $24(3.35)$ & $70(8.04)$ & $18(0.56)$ & $3(0.42)$ & $7(0.80)$ \\
\hline 1999 & $161(5.21)$ & $17(2.55)$ & $54(6.39)$ & $15(0.49)$ & $0(0.00)$ & $6(0.71)$ \\
\hline 2000 & 126 (4.29) & 24 (3.93) & 44 (4.84) & $20(0.68)$ & $3(0.49)$ & $6(0.66)$ \\
\hline 2001 & $144(5.05)$ & $19(3.46)$ & 58 (6.95) & $25(0.88)$ & $3(0.55)$ & $11(1.32)$ \\
\hline
\end{tabular}


The trend that we have described in low birth weight has implications for later life, as low birth weight has been implicated as a risk factor for a number of chronic adult diseases. ${ }^{20}$ While biological programming may mediate the link between low birth weight and adult disease, socioeconomic factors may also contribute. Bartley et $\mathrm{al}^{21}$ showed that low birth weight is associated with socioeconomic disadvantage in childhood and adolescence and with financial disadvantage at age 23 years.

There is evidence that targeting areas of deprivation may improve birth outcomes. Oakley et al, ${ }^{22}$ in a randomised controlled trial comparing antenatal social support with standard antenatal care in a socially disadvantaged population, showed that mothers receiving the intervention had babies with a higher mean birth weight, and fewer very low birth weight babies. The intervention mothers required fewer hospital admissions during pregnancy. They were more likely to experience spontaneous onset of labour and were less likely to require epidural anaesthesia. Intervention group mothers and babies were significantly healthier in the early postnatal weeks than controls. Teranishi et $\mathrm{l}^{23}$ examined the influence of socioeconomic status on growth to 23 years in the 1958 British birth cohort. For low birth weight babies, catch up growth in height was more pronounced in social classes I and II than in other classes.

There are a number of potential weaknesses in our study. Did the exclusion of 6766 singleton births invalidate the deprivation score analysis? Analysis of the distribution of Townsend scores in the 2893 exclusions where there was a valid postcode showed that 949 (10.2\%) were from the least deprived Townsend quartile and 522 (4.9\%) were from the most deprived quartile. This indicates a potential bias, greatest in the least deprived group, that could have reduced the number of births in the early years of the study when the documentation of postcodes was least reliable. Reliance on the last menstrual period to calculate gestational age rather than ultrasound scanning could have influenced the calculation of the SDS for birth weight, as it tends to decrease the SDS. ${ }^{14}$ However, when the mean SDS for birth weight in the first six years of the study (when gestational age was calculated from the date of the last menstrual period) was compared with the last six years of the study no difference could be found.

It is not clear whether our findings are specific to the Wirral, or whether similar trends have occurred nationally. We suggest that routinely collected birth information and a suitable area based deprivation score should be more widely used to monitor trends. Currently, reliance on joint registration of births using the father's occupational social class means that the most vulnerable group of mothers and babies may be missed.

\section{Conclusion}

We have shown that in the Wirral over the last 12 years, the reduction in live births has not been evenly distributed among social groups but has been significantly less pronounced in the most deprived areas. This increasing social inequality is further aggravated by the fact that the proportion of low birth weight babies has risen significantly in the most deprived areas of the Wirral compared with the least deprived areas. These public health findings are important to policy makers, as well as clinicians in maternity and primary and secondary care.

\section{ACKNOWLEDGEMENTS}

We acknowledge the help of Dr Melanie Maxwell, Director of the Clinical Practice Research Unit, Wirral Hospital NHS Trust and staff members of the Wirral Health Informatics Service.

\section{Authors' affiliations}

P Bundred, Department of Primary Care, University of Liverpool, Liverpool, UK

D Manning, B Brewster, Neonatal Unit, Wirral Hospital NHS Trust, UK I Buchan, Population Health Unit, School of Epidemiology and Health Sciences, University of Manchester, Manchester, UK

\section{REFERENCES}

1 Office for National Statistics. Birth statistics: births and patterns of family building England and Wales 2000. Series FM1 no 29. London: ONS, 2000.

2 Office for National statistics. Mortality statistics: childhood, infant and perinatal series 2000. Series DH3 no 33. London: ONS, 2000.

3 Spencer N, Bambang S, Logan S, et al. Socioeconomic status and birth weight: comparison of an area-based measure with the Registrar General's social class. J Epidemiol Community Health 1999:53:495-8.

4 Townsend P, Philimore P, Beattie A. Health and deprivation: inequality and the North. London: Croom Helm, 1988.

5 Bambang S, Spencer NJ, Logan S, et al. Cause-specific perinatal death rates, birth weight and deprivation in the West Midlands, 1991-93. Child: Care, Health and Development 2000;26:73-82.

6 Guildea ZES, Fone DL, Dunstan FD, et al. Social deprivation and the causes of stillbirth and infant mortality. Arch Dis Child 2001;84:307-10. 7 Child Growth Foundation. UK cross-sectional reference data: 1990/1 London: Child Growth Foundation, 1991.

8 Manchester Information \& Associated Services. Postcode-Enumeration District Directory. http://census.ac.uk/cdu/ datasets/. Manchester: Manchester Information \& Associated Services, 2001.

9 Agresti A. Categorical data analysis. New York: Wiley, 1990.

10 Hollander M, Wolfe DA. Non-parametric statistical methods. 2nd ed. New York: Wiley, 1999.

11 Armitage P, Berry G. Statistical methods in medical research. 3rd ed. Oxford: Blackwell, 1994.

12 StatsDirect Ltd. StatsDirect statistical software. http:// www. statsdirect.com. StatsDirect Ltd, 2002.

13 Gretch V, Savona-Ventura C, Vassallo-Agius P. Unexplained differences in sex ratios at birth in Europe and North America. BM 2002;324:1010-1.

14 Elmén H, Hoglund D, Karlberg $P$, et al. Birth weight for gestational age as a health indicator. Eur J Public Health 1996;6:137-41.

15 Spencer NJ, Logan S, Gill L. Trends and social patterning of birthweight in Sheffield, 1985-94. Arch Dis Child Fetal Neonatal Ed 1999;81:F138-40.

16 Alberman E. Are our babies becoming bigger? J R Soc Med 1991:84:257-60.

17 Dowding VM, Barry C. Cerebral palsy: social class differences in prevalence in relation to birthweight and severity of disability. $J$ Epidemiol Community Health 1990;44:191-5.

18 Richards $M$, Hardy R, Kuh D, et al. Birth weight and cognitive function in the British 1946 birth cohort: longitudinal population based study. BM 2001;322:199-203.

19 Matte TD, Bresnahan M, Begg MD, et al. Influence of variation in birth weight within normal range and within sibships on $I Q$ at age 7 years: cohort study. BM 2001;323:310-14.

20 Barker DJP. Fetal and infant origin of adult disease. London: BM Publishing Group, 1992

21 Bartley M, Power C, Blane D, et al. Birth weight and later socioeconomic disadvantage: evidence from the 1958 British cohort study. BM 1994;309:1475-9.

22 Oakley A, Rajan L, Grant A. Social support and pregnancy outcome. Br J Obstet Gynaecol 1990;97: 155-62.

23 Teranishi H, Nakagawa H, Marmot M. Social class difference in catch up growth in a national British cohort. Arch Dis Child 2000;84:218-21.

\section{COMMENTARY}

Kramer et al state "Among the most robust findings in perinatal epidemiological research are the large socioeconomic disparities in such key pregnancy outcomes as perinatal and infant mortality, low birthweight, intrauterine growth restriction and preterm birth" (p 194). Given the association of poor pregnancy outcomes with adverse health outcomes in infancy, childhood, and adulthood, the issue of trends in social disparities takes on particular significance. If the disparities are increasing, as suggested by Bundred et al, this has implications for health inequalities across the lifecourse and is likely to compromise government targets aimed at reducing these inequalities. ${ }^{2}$

The paper offers useful insights into social trends in birth rates and birth weights. The trend to increasing disparity in 
birth numbers between the most and the least deprived quartiles in the Wirral over the last 10 years is striking. Although the trend cannot be assumed to be happening across the country, it represents a significant demographic and social change in the Wirral. It suggests that a higher proportion of children are being born into relatively deprived homes, with implications for the future health and wellbeing of the Wirral population. The proportion of low birth weight infants $(<2500 \mathrm{~g})$ born in the least deprived quartile fell disproportionately over the 12 year period studied compared with the proportion in the most deprived quartile. I am not aware of other studies showing a similar divergence in low birth weight trends between areas with different levels of deprivation. If this finding is confirmed, health inequalities in infancy and later childhood are likely to increasingly jeopardise government targets.

The finding of a consistent year-on-year finely graded decrease in mean birth weight standard deviation scores with increasing deprivation is consistent with the results reported by Elmen $e a^{3}$ from the Swedish city of Goteborg. This is an important finding showing that the social gradient in birth weight is independent of gestational age, and the social differences in pregnancy outcome are not simply dependent on reducing social differences in preterm birth.

The study findings suggest worrying trends in the social patterning of birth rates and birth weights in the Wirral over the last 12 years. However, caution should be exercised in extrapolating from these results to the rest of the country. The mean birth weights for singleton births in the Wirral shown in table 2 are consistently higher than those we reported in our studies from the West Midlands (1991-1993) ${ }^{4}$ and Sheffield (1985-1994). ${ }^{5}$ This suggests that the Wirral population is more affluent, with fewer births to mothers of Indian subcontinental origin. As might be expected with routinely collected data, a high proportion $(>16 \%$ ) of births are excluded because of missing data. In addition, the numbers are too small to adequately assess trends in the clinically important births $<1500 \mathrm{~g}$. Thus trends in the Wirral may be unrepresentative of trends elsewhere, and the combination of missing data and relatively small numbers may distort the study findings.

These methodological shortcomings notwithstanding, this study represents an important contribution to the literature on social disparities in pregnancy outcomes in the United Kingdom, suggesting trends in the social patterning of birth rates and birth weights with considerable public health significance. It highlights the need for further studies in different parts of the country to explore trends in birth rates and weights using postcoded, routinely collected data and birthweight standard deviation scores. Monitoring trends in pregnancy outcomes at the national level is urgently needed as part of monitoring progress towards government health inequality targets.

\section{N Spencer}

School of Postgraduate Medical Education, University of Warwick, Coventry CV4 7AL, UK; n.j.spencer@warwick.ac.uk

\section{REFERENCES}

1 Kramer MS, Séguin L, Lydon J, et al. Socio-economic disparities in pregnancy outcome: why do the poor fare so poorly? Paediatr Perinat Epidemiol 2000;14:194-210.

2 Department of Health. Health inequalities: Health Secretary announces new plans to improve health in poorest areas: 28 February 2001. http://www.doh.gov.uk/healthinequalities/press.htm

3 Elmén $\mathbf{H}$, Höglund $D$, Karlberg $P$, et al. Birth weight for gestational age as a health indicator: birth weight and mortality measures at a local area level. Eur J Public Health 1996;6:137-41.

4 Spencer NJ, Bambang S, Logan S, et al. Socioeconomic status and birth weight: comparison of an area-based measure with the Registrar General's social class. J Epidemiol Community Health 1999:53:495-8.

5 Spencer NJ, Logan S, Gill L. Trends and social patterning of birthweight in Sheffield, 1985-1994. Arch Dis Child Fetal Neonatal Ed 1999;81:F138-40. 